\title{
EFFECT OF EPOXY ADDITION ON COMPRESSIVE STRENGTH, FLEXURAL AND ULTRASONIC PLUS VELOCITY OF CEMENT MORTAR
}

${ }^{\star}$ Mohmmed J. Mohmmed ${ }^{1}$
Khalid M. Owaid ${ }^{1}$

Raouf M.Raouf ${ }^{1}$

1) Materials Engineering Department, College of Engineering, Mustansiriyah University, Baghdad, Iraq

\begin{abstract}
This study aims to study the compressive strength and ultrasonic pulse velocity of mortar which contains epoxy composed of two parts: resin and hardener, at 5, 10, 15, and 20 (wt. \%) of epoxy content at different ages $(7,28)$ days. Where the results showed an increase in the value of compressive strength gradually and the highest at $15 \%$ of epoxy content (64.6, and 69.4 $\mathrm{MPa})$ at $(7,28)$ day, respectively.
\end{abstract}

Keywords: polymer cement composite; Mortar; pulse velocity; compressive and flexural strength

\section{Introduction}

There have been several studies on polymer blended mortar, polymer-modified mortar, and polymer mortar throughout the years. Polymer modified mortar is a complex material that comprises 2 solid stages: Assembles continuously by material a binder containing the cementation phase and the polymer phase. Polymer-modified mortar is made by mixing polymer or monomer with fresh cement mortar. Composites in dispersed, dry, or liquid form and then curing. Currently, these materials are mainly used as common construction materials due to their comparative performance, multifunctional, and stability in the evaluation of conventional cement concrete. The properties of the composite material are not only derived from its components, but also the synergistic effect [1]. Polymer composites have been used in a wide range of industrial applications in the last two decades, including construction and automobiles, owing to their advantages over metal materials, including good relative mechanical properties, less damage to processing equipment, high strength-to-weight ratio, chemical resistance, low density and lower cost [2]. Thermoset and thermoplastic polymers have recently been mixed with natural fillers to create composites with improved strength and fracture resistance. Inert fillers, despite their name, can alter the compound's other qualities in addition to the cost. They may, for example, improve hardness, minimize shrinkage, and raise the density of the compound. The use of inexpensive and readily accessible fillers, such as industrial particlereinforced polymer composites, to make a lowcost composite. Industries produce a large quantity of the garbage, which causes major environmental issues. As a reinforcing phase, industrial wastes provide high mechanical, simplicity of manufacture, and cheap cost and other qualities [3]. The characteristics of "epoxy resin mortar" count on the components of the mortar. As a result, optimizing the epoxy resin mortar mix percentage is required for a practical repair scheme, as well as avoiding or reducing a mismatch in the characteristics of the substrate

*Corresponding Author: EBMA018@uomustansiriyah.edu.iq 
concrete and repair mortar. [4,5] Recycling waste materials like steel slag results in environmentally friendly construction components, lightweight and low-cost while also reducing the health and environmental problems and landfilling.

\section{Aim}

The aim of this work is to investigate compression and ultrasonic pulse velocity tests, by addition epoxy to cement mortar.

\section{Experimental Work}

\subsection{Materials}

\subsubsection{Cement}

Cement that has been utilized in this work was Sulfate-resistant Portland cement (SRC), which is commercially referred to as (Al- Geser, manufactured in Al-Sulaymaniyah, Iraq.) The physical and chemical analyses have been carried out by the National Centre for Labs and Construction Research. The test results have indicated the fact that Al- Geser complied with the Iraqi standard specifications (IQS) No5 / 1984. [6] The physical characteristics and the chemical composition of Al- Geser have been listed in Table1.

Table 1. Cement physical qualities and chemical composition

\begin{tabular}{llll}
\hline Test types & Properties & Test result & $\begin{array}{l}\text { Spec. Limit } \\
\text { according } \\
\text { to IQS } \\
\text { No5:1984 }\end{array}$ \\
& & & \\
& & & \\
Physical & Setting time & & \\
properties & -Initial & $2: 15$ & \\
& setting & $4: 15$ & \\
& -Final & & \\
& setting & & \\
& Compressive & & \\
& strength & & \\
& (MPa) & 19.5 & \\
& -3day & 25.5 & \\
& -7days & & \\
& & & \\
&
\end{tabular}

$\begin{array}{lll}\text { Soundness } & -0.1 & \leq 0.8\end{array}$

Fineness

(m2/Kg)

(blains

358

$\geq 250$

method)

\begin{tabular}{|c|c|c|c|}
\hline \multirow{9}{*}{$\begin{array}{l}\text { Chemical } \\
\text { composition } \\
\text { and } \\
\text { properties }\end{array}$} & $\mathrm{SiO}_{2}$ (wt.\%) & 19.74 & - \\
\hline & $\begin{array}{l}\mathrm{Al}_{2} \mathrm{O}_{3} \\
\text { (wt.\%) }\end{array}$ & 4.28 & - \\
\hline & $\begin{array}{l}\mathrm{Fe}_{2} \mathrm{O}_{3} \\
\text { (wt.\%) }\end{array}$ & 5.04 & - \\
\hline & $\mathrm{CaO}$ (wt.\%) & 64.13 & - \\
\hline & $\begin{array}{l}\text { Lime } \\
\text { saturation } \\
\text { factor(LSF.) } \\
(\%\end{array}$ & 0.98 & $0.66-1.022$ \\
\hline & $\mathrm{MgO}$ (wt.\%) & 2.92 & $\leq 5$ \\
\hline & $\mathrm{SO}_{3}$ (wt.\%) & 2.36 & $\leq 2.5$ \\
\hline & $\begin{array}{l}\text { Loss on } \\
\text { ignition } \\
\text { (wt.\%) }\end{array}$ & 3.92 & $\leq 4$ \\
\hline & $\begin{array}{l}\text { Insoluble } \\
\text { residue } \\
\text { (wt.\%) }\end{array}$ & 0.96 & $\leq 1.5$ \\
\hline
\end{tabular}

\subsubsection{Fine Aggregate}

Natural fine aggregate (Al-Ekadir region/ Karbala Governorate) was used as part of this work. According to the Iraqi Specification No.45 of 1984 for Cement. [7] As shown in Table (2).

Table 2. Grading of fine aggregates.

\begin{tabular}{ccc}
\hline $\begin{array}{c}\text { Sieve size } \\
(\mathbf{m m})\end{array}$ & $\begin{array}{c}\text { \% Passing by } \\
\text { Weight }\end{array}$ & $\begin{array}{c}\text { Specific } \\
\text { Limit }\end{array}$ \\
\hline 4.750 & 92.30 & $90.0-100.0$ \\
2.360 & 83.70 & $70.0-100.0$ \\
1.180 & 73.90 & $55.0-90.0$ \\
0.600 & 51.80 & $53.0-59.0$ \\
0.300 & 20.20 & $8.0-30.0$ \\
0.150 & 4.60 & $0.0-10.0$ \\
Salts Percentage \% & 0.400 & $\leq 0.50$ \\
\hline
\end{tabular}




\subsubsection{Polymers}

Epoxy type (Eporip EN1504-4) is used in all the experiments. The characteristics of a popular epoxy resin are shown in Table 3. Epoxy has two components: Hardener and resin. The hardener reacts with the resin and hence it is converted from viscous liquid to a hard solid material (i.e., Polymer with a high molecular weight). Study, a ratio of 1 part of hardener to 3 parts of resin (by weight) is used. In general, when compared to other types of thermoset polymer resins, epoxy has superior mechanical qualities at a reasonable cost and high adhesion quality.

Table 3. Typical characteristics of epoxy from a supplier

\begin{tabular}{cc}
\multicolumn{2}{c}{ supplier } \\
\hline Characteristics & $33 \%$. \\
Elongation & $70(\mathrm{mpa})$ \\
Compressive strength & $39(\mathrm{mpa})$ \\
Tensile strength & \\
\hline
\end{tabular}

\subsection{Mix Preparation Margins}

At $5 \%, 10 \%, 15 \%$, and $20 \%$ by weight, four mortar groups were made using resin epoxy without hardener. The maximum amount was limited to $20 \mathrm{wt}$, and the minimum resin epoxy concentration of $5 \mathrm{wt}$. Percent (\%) was chosen based on workability. Percent due to epoxy segregation of the mortar mixture.

\subsection{Testing}

\subsubsection{Compressive Strength Test}

The compression test is used to predict the strength of a polymer-cement composite before it fails. Despite the change in percentage mixture, the compression test was calculated according to "ASTM C109/C109M-13" [8] (Using 2-in. or [50-mm] cube Specimens) although the difference in proportion mixture.

Specimens were loaded uniaxially with a loading rate of $2.5 \mathrm{KN} / \mathrm{s}$ and a capacity of $250 \mathrm{KN}$ using a universal press machine (ser comp, control co., Italy). For all specimens, the test was performed at the same loading speed. The compression strength is then estimated by dividing the load on the specimen's cross-sectional area using the equation:

Compressive strength $=$ Load/area

\subsubsection{Flexural Strength Test}

It represents the greatest stress experienced within the material at its moment of rupture. It is measured in terms of stress. The capacity of brittle material to withstand deformation under load is defined as a mechanical parameter. The most common test is the transverse bending test, which involves bending a rectangular crosssection specimen until it is yielding or fractures. The test was performed according to ASTM C348 [9]. A rectangular cross-section (100 $\times 25 \times 25$ ) $\mathrm{mm}$ block is supported by two supports at a loading rate of $1.8 \mathrm{kN}$ per second using a calibrated testing equipment (Sercomp, Controls Co. Italy).

\subsubsection{Ultrasonic Pulse Velocity Test}

This test was performed using a portable ultrasonic non-destructive indicating tester (PUNDIT Lab PROCEQ Co.) Switzerland by British standard BS 1881: part 203 [10]. The instrument cables were fitted with two transducers, one of which served as a transmitter and the other as a receiver for ultrasonic pulses. Using a coupling agent, both transducers are placed on the surface of the specimen to guarantee excellent impulse transmittance. To achieve proper contact, petroleum jelly or grease was placed between the contact faces of the transducers and the tested surfaces of the specimen. An electro-acoustical transducer created a pulse of longitudinal vibration with resonance frequencies of $54 \mathrm{kHz}$ in this test, which was subsequently translated into an electrical signal by a receiver transducer. Utilizing an electronic timing circuit, the pulse transit time is applied. Pulse velocity (V) in 
$(\mathrm{m} / \mathrm{sec})$ is calculated according to the following equation:

$V=L / t$

Where $\mathrm{t}=$ transit time (micro sec.)

$\mathrm{L}=$ distance among centers of transducer faces (m)

\section{Results and Discussion}

\subsection{Compression Test}

Fig. 1 shows the compressive strength values for various polymer-cement composites ratios cured at 7 days: $47.2,54.4,63.6$ and $44.3 \mathrm{MPa}$ at 5, 10, 15 , and $20 \%$, respectively (1). Compressive strength of (28-day) cured specimens, on the other hand, is 51.6, 58.2, 68.4 and 46.2 MPa for $5,10,15$, and 20\%, respectively. Compressive strength of (28-day) cured specimens, on the other hand, is 51.6, 58.2, 69.4, and 48.6 MPa for $5,10,15$, and $20 \%$, respectively. The improvement in compressive strength after the curing process is clearly related to a greater adhesion between the matrix and the filler. The stress transmission and interlocking between the mortar the matrix and filler cause the compressive strength to decrease when $20 \%$ polymer-mortar composites are used.

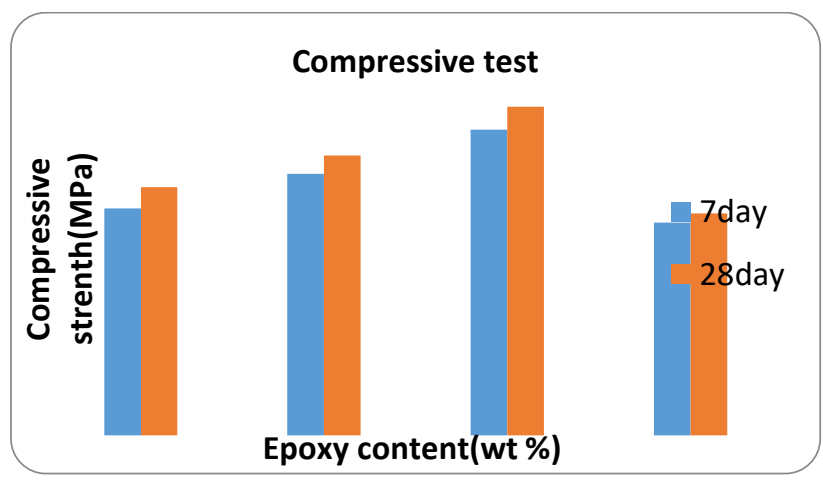

Figure 1. The compressive strength of various polymermortar composites after $(7,28)$ days of curing.

\subsection{Flexural Strength Test}

The flexural strength as shown in Fig. 2 of the prepared polymer-mortar are varying between
$(12.23,15.78,17.48,11.22) \mathrm{MPa}$ for $(5,10,15$, $20 \%$ ) respectively for the (7day) cured specimens. The values of the flexural strength at (28day) curing are varying between $(15.86,18.4$, $19.55,13.32) \mathrm{MPa}$ for $(5,10,15,20 \%)$ respectively. As the polymer percentages (20\%) the flexural strength decrease as this could be attributed to the addition of higher percentage of polymer, leading to formation of agglomeration tendency.

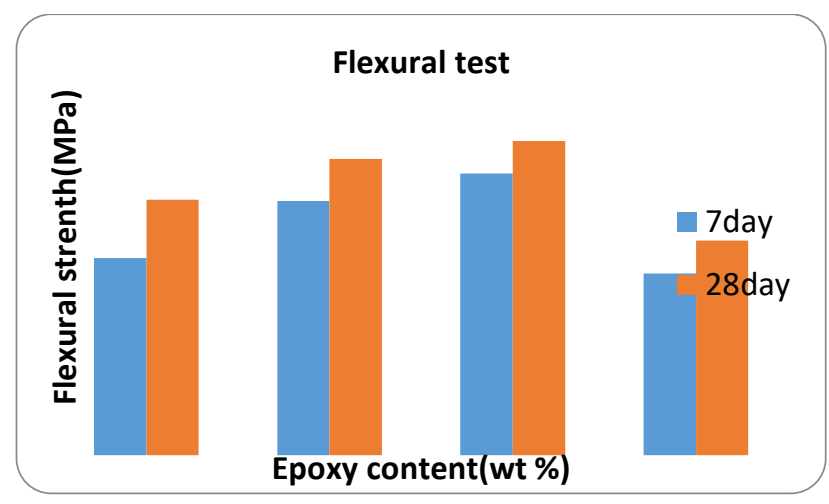

Figure 2. The compressive strength of various polymermortar composites after $(7,28)$ days of curing.

\subsection{Ultrasonic Test}

The velocity values for various polymer mortar composites. Due to increased adhesion, a high polymer percentage improves uniformity and eliminates voids between fillers. The velocity of polymer-mortar composites for the (28 day) cured is higher than (7 day) due increase in crosslinked that leads to increases the homogeneity of the composites.

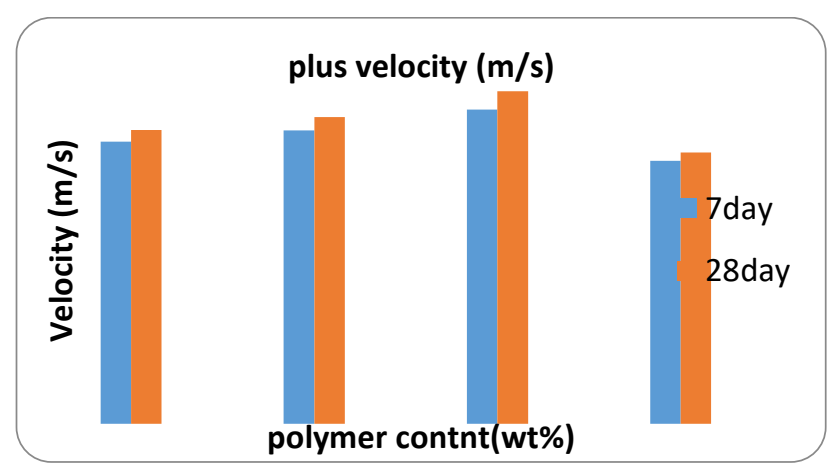

Figure 3. The velocity of different polymer -cement at $(7,28)$ day curing. 


\section{Conclusions}

The following is a summary of the study's findings:

1. Adding epoxy resin to mortar has an impact on its properties and reduces greatly its brittle nature.

2. Interestingly, epoxy can improve the flexural and compressive strengths of mortar for different cured.

3. The best mechanical properties can be obtained using $15 \%$ percentage of polymer.

4. The velocity values of the various polymer mortar composites increase as cross-linking increases, resulting in a rise in the homogeneity of the composites.

5. As the polymer percentages $(20 \%)$ the flexural strength and compressive strength decrease as this could be attributed to the addition of higher percentage of polymer, leading to formation of agglomeration tendency.

\section{Acknowledgements}

Authors are grateful to all support given by college of Engineering, University of Mustansiriyah for supporting.

\section{Conflict of Interest}

The author confirms that the publication of this article causes no conflicts of interest.

\section{References}

1. Ganesan, S., et al. 2014 Performance of polymer modified mortar with different dosage of polymeric modifier. In MATEC Web of Conferences. EDP Sciences.

2. Agarwal, B. D. and Broutman, L. J. 1990, "AnalysisandPerformanceof Fiber Composites", 2nd Ed., Wiley, New York, pp448,.
3. Raju G. U., Gaitonde V. N., Kumarappa S. 2012, "Experimental Study on Optimization of Thermal Properties of Groundnut Shell Particle

Reinforced Polymer Composites", Int. J. Emerg. Sci., vol 2 (3), pp 433-454,.

4. Decter, M.H. 1997 Durable concrete repair-Importance of compatibility and low shrinkage. Constr. Build. Mater., 11, 267-273.

5. Karade, S.; Lakhani, R.; Asthana, K.K 2006. Evaluation of repair materials: Issues and methods. Constr. Build. Mater. World, 11, $152-168$.

6. Iraqi Reference Guide indicative (198) and the Ministry of Planning/Central Agency for Standardization and Quality Control Manual 198/1990.

7. Standard Iraqi Specification number (45) to the age 1984" Aggregate of natural resources used in the concrete construction."

8. ASTM C 109/C 109M Standard Test Method for Compressive Strength of Hydraulic Cement Mortars (Using 2-in. or [50-mm] Cube Specimens) August 2008.

9. ASTM D 790 - 02, 2002 "Standard Test Methods for Flexural Properties ofUnreinforced and Reinforced Plastics and ElectricaInsulating Materials",.

10. British standard BS1881: part 203:1986, 2003. 